\title{
Fintech and the Socialization of the Financial Industry
}

\author{
Antonio F. Miguel \\ ISCTE-Instituto Universitário de Lisboa (ISCTE-IUL) \\ Business Research Unit (BRU-IUL), Lisboa, Portugal \\ Lucie Duval \\ ISCTE-Instituto Universitário de Lisboa (ISCTE-IUL)
}

\begin{abstract}
Fintech have known an incredible exposure over the last years, attracting investments of large billions of dollars. Fintech are the match between finance and technology and they are imposing a new way of thinking in all the branches of the financial industry. After the financial crisis of 2008, people have changed their way of seeing "Finance" and, more particularly, the role of banks, looking for products and services that correspond to their needs. Moreover, the financial crisis has highlighted a relevant number of dysfunctions on the banking sector and on the financial regulation. Regulators have strengthened their requirements for banks, particularly in their relations with clients. These have opened a breach for Fintech companies and they are using it. Fintech companies rely on a different value proposition to clients that is based on a timesaving, fast and clear experience. Indeed, they propose major innovations in products and processes. Fintech companies put the client back at the center of all their attention and clients are now the top priority.
\end{abstract}

Keywords: Fintech, Financial Industry, Innovation, Customers.

\section{JEL Classification: G18; G21; G28}

\section{Introduction}

The first appearance of the Fintech was in 1950's nevertheless with the 2007-2008 crisis it has expanded on a proportion never seen before. Definitely the financial crisis of 2007-2008 has led to numerous shifts in terms of liquidity and capital for banks. Indeed, after this crisis, consumer's behavior, regulation and technologies have been submitted to changes and have redefined the financial environment. This crisis has opened the barriers to new competitors on a proportion never seen before (Worthington and Welch, 2011). There is a socialization of the finance Industry meaning that, due to various shifts, the Finance is internalizing all the new element of the surrounding environment. The purpose of this paper is to study this socialization of the finance industry

The new competitors in the financial industry are called Fintech, the aggregation of financial services and technologies. Since several years, this phenomenon of Fintech has attracted a lot of attention from media, investors and "established financial institutions". Indeed, Fintech represent a new type of companies that use innovation and creativity in order to rethink "traditional" finance services, products and clients' experience. Nevertheless, how are these financial technologies revolutionizing the financial industry? Fintech start-ups are "attacking" the banking system by proposing to clients a totally different approach. In fact, nowadays competitive pressures are coming from various companies, banks and non-banks, pushing banks to get out of their comfort zone and to rethink their business model (Perrott, 2008).

\section{Why has the Finance environment changed?}

\subsection{The change of consumers' behavior accompanied by the technological evolution}

The 2007-2008 financial crisis has led to a lot of changes in the financial industry. Indeed, this crisis has tarnished the reputation of many banks creating an opportunity for "nonbanks" to provide an improved and different service to customers.

If banks once inspired an almost reverential fear, it is no longer the case and there are many reasons for dissatisfaction and distrust that emphasize the relational gap accumulated over the crisis period. Customers are more and more upset of the commercial aggressiveness of banks seeking to sell banks' products. The constant turnovers of advisors, the lack of transparency in proposals as well as the rates and conditions practiced have emphasized the defiance regarding banks. 
After the crisis, the anger of customers regarding banks has increased once again leading them to consider alternative providers (Worthington and Welch, 2011). Banking customers have become mistrustful towards banks; at least $70 \%$ of their customers think that banks are not acting in their best interests (Hedley, Roche, and Banerjea, 2006). Customers are seeing banks as opaque companies making money thanks to their current account, by charging overdraft or interest paid on credit balances (Worthington and Welch, 2011).

Nevertheless, customers are mistrustful towards banks but also towards central banks. In 2016, the CEO of Bitcoin Exchange Coinfloor state that, "People don't trust central banks (...) That's less of a problem in the Eurozone and it is huge problem in emerging market. In countries like Nigeria, Argentina, and Venezuela, currencies are going down by $10 \%, 20 \%$ and $80 \%$ a year in some cases. You don't trust the central bank in that scenario and you shouldn't." (Nwosu, in Marketing week, February 2016).

Demands from customers toward financial services companies are multiple. They want an easy-use, automation, twenty-four-hour access and more transparency (Goldman Sachs, 2015). Regarding their relationship with financial services they are looking for a fast reactivity and a real personalization of the services they are offered (Klein, 2015).

According to the World Retail Banking Report (2015), the quality of the customers' experience is stagnating and customers' loyalty is deteriorating. Moreover, this report highlights that there is an increase on the percentage of customers' that have a negative experience with banks.

In 2009, Virgin Money (Virgin Group) studied their potential to enter into the financial services market. The results showed that customers were demanding, but believed that Virgin Money would be seen as a trusted deposit taker and mortgage lender (Worthington and, Welch, 2011). Companies like Virgin Money and Tesco are bringing a new approach to services and products. The best example would be the insurance pack; club cardholders can take a pack in store and check out with their spending. This approach for consumers is timesaving and it is easy to use.

Consumers' behavior is changing the environment of the financial services by creating new accesses. The globalization has also changed consumers' behavior by increasing their interaction with the "world". More and more customers are using the same products, technologies and networks for instance the software Windows developed by Microsoft (Mikoajewicz-Woniak, and Scheibe, 2015). However, the changing in customers' behavior has to be joined to technologies. The concept of technologies has been studied for many years and "refers to all of the tools, techniques and procedures used by individuals to perform a specific task" (Reisman and Zhao, 1991).

The new technologies have been a facilitator to entry for Fintech companies, as the merger "of big data analytics and new distribution channels allowed technology start-ups to disrupt traditional banks" (Goldman Sachs 2015). In fact, new technologies are giving to new entrants the possibility to taking parts of a market that is underserved by banks. For instances, one example of an underserved service are the international money transfers. World Bank Report (2015) shows that, in 2014, approximately $\$ 550 \mathrm{bn}$ was sent internationally and banks only handled $\$ 30 \mathrm{bn}$. Moreover, innovation has driven the evolution of these new technologies. Economic growths, progress in living norms are consequences of innovation in all industries. Innovations in the financial industry have been motivated by the desire to meet the needs of the changing society (World Economic Forum, 2015). For example, payment methods have tremendously changed over years in order to comply with consumer trends and needs. Between 2008 and 2014, the number of checks in circulation has decreased by $29 \%$, underlying the fact that the payment method is becoming more and more electronic (Cichowlas, 2015). Another example is, through the EU integration, the appearance of the SEPA (Single Euro Payment Area). Electronic payment through Europe became as easy as cash payment. A customer has the possibility to make a rapid and secure transfer to any person located in the Euro area in just a single click. Thanks to these technological innovations, finance has been democratized and has allowed customers to access to a broader range of services and products (Goldman Sachs, 2015).

The new technologies have permitted customers to be more active and involve in their interactions with companies and with each other's. The value proposition and the customer experience are driven by the consumer itself thanks to his increase of knowledge in technologies (World Economic Forum, 2015). Consumers have become "prosumers", meaning that they have two roles: (1) in one way, they are consumers of what companies offer and, (2) in another way, they are also producers, because they are performing tasks previously reserved to producers (Mikoajewicz-Woniak and Scheibe, 2015). A new era is coming, where people are receiving the message but they are also creating it, i.e., the "cooperation area" (Kotler, Bowen, and Makens, 2010). Internet has made a notable progress for the last few decades. It has allowed customers to save time and effort by having access to many services and products (Takieddine and Sun, 2015). Furthermore, through Internet, companies have been able to do a better marketing product and distribution (Tih and Ennis, 2007). 
The appearance of the self-service technologies (SSTs) has changed the way customers are seeing services. The selfservice technology model can be seen as the "branch of the future" permitting customers to have an easy, fast and secured experience based on innovative technology (Tellervision and Mars, 2016). In the banking industry, the appearance of the automated teller machines, mobile and internet banking have reduced human interactions. More and more services are digitalized and customers are granted value from it. It has been found that customers using SSTs are more pleased and spread a positive word-of-mouth around them. Services such as self-checkout in supermarkets, internet check-in for a flight, are more "place and time convenient" (Yand and Klassen, 2008).

The early implementation of SSTs in the 1980's or 1990's has not been completely accepted by customers, as they were not enough mature to understand and to trust technologies. Nevertheless, nowadays customers are becoming more and more comfortable with it. The popularity of the SSTs is also coming from conveniences given to parties, the customer and the supplier. With time, customers saw the benefit from it, they started using it and thought it was faster, easier and that it allowed them to have a better control on their activities (Meuter, Ostrom, Roundtree, and Bitner, 2000). Traditionally face-to-face relationship is relevant in financial services. However, with the SSTs, face-to-face has been decreasing and now the customers' impression of its financial services rely on their experiences when using banks' websites (Eriksson and Maquardt, 2001). Indeed, the internet can reinforce client's relationship nevertheless one major drawback is when the SSTs experience is unfortunate; clients become frustrated (Pujari, 2004).

Improvements in Internet technologies are shifting the architecture and the essence of financial services; it facilitates the entrance of new financial services providers (Shahrokhi, 2008). Overall, technologies changes are pushing the financial sector to increase their quality to customers, to lower their costs and to broaden the access to financial services. The e-finance has been defined in two different ways. Allen, McAndrews, and Strahan (2002: 7), define $e$ financeas "The provision of financial services and markets using electronic communication and computation. Efinance activities include all types of financial activities carried out over the cyberspace or other public networks, such as online banking, electronic trading, provision and delivery of various financial products and services such as insurance, mortgage and brokerage." Fight (2002:23) defines e-finance as "all which relates to the linking of business, finance, and banking via electronic means, encompassing information gathering, processing, retrieval, and transmission of data as well as the transmission, purchase, and selling, of goods and services."

E-finance has not been creating by the development of internet by rather by the Western Union Corporation, which has been the first one to introduced the "distant money transfer"; in 1914 it proposed the first "consumer charge card" (Shahrokhi, 2008). Even if the e-finance has existed for a long-time, the developments of the internet and communication technologies have seriously changed it. E-finance is redefining the value proposition made to customers, the communication system between the finance services providers and customers. Indeed, e-finance has broken the habits of doing business and has defined the new economy (Fight, 2002). The development of technologies has disintegrated the essence of what used to make banks peculiar (Shahrokhi, 2008). Moreover, it has constructed a global and competitive environment. This has permitted the development of talents ready to create new concepts and models. The evolution of the $e$-finance has benefited too global customers. It permits to customize and to develop sophisticated services improving the quality and the effectiveness of their quality (Claessens, Glaessner, and Klingebiel, 2000).

As mentioned before, customers are looking for fast and less time-consuming services. In order to answer to these requirements, new services using internet have appeared. There are platforms matching businessperson and risk capital investors according to the purpose, amount and business industry of the investment. These platforms create matches in a short time, which benefit both businesspersons and investors. This is a sound example of electronic fund. WR Hambrecht \& Company, an investment banking company has been an avant-gardist in electronic Initial Public Offers (IPO's). With the traditional method, clients gave the bid price and size interest to promoters in order for them to settle an allocation. With the electronic method, there are no longer promoters; clients put the bid price and size interest electronically (Shahrokhi, 2008). The major improvement in these situations; either the platform or the IPO: is the speed of information. Thanks to internet, in only a few clicks, accessing millions of information in few minutes is possible.

Over the years, the society has encountered a quick modification of its direction, going from an industrial to an information technology society (Howcroft, 2003). The customer has also changed, he is more aware of technologies and he requires more qualities in services. Even if these have shifted the financial services it is not the only reasons.

\subsection{The Regulation driving the shift of the Finance Industry}

The 2007-2008 financial crisis has underlined all the dysfunction of the banking sector and financial regulation. It emphasized the fact that the prudential regulation did not avoid the disaster, because it did not focus enough on illiquidity risks and on the asset leverage level. 
The market discipline did not show any signals and the internal controls showed that suspicious dealings were going on across the world. Krugman (1999) state that, "Societies are learning from crises and particularly from the financial ones. These crises are coming back over and over and they are coming from where we do not forecast them."

For several decades, innovation in the financial sector was essentially innovation on the financial products, responding to the growing deregulation and the increase of the cost of risk. In fact, over the last decade, innovation was seen as financial creativity constituting major characteristics to the financial and banking sector showing its capacity to adapt (Gowland, 1991). Every bank was looking for innovation in their financial technics in order to remain an unavoidable actor of the finance sector. However, nowadays financial innovations are no more up to date, the structure of operations is becoming more standardized; innovations are mainly driven by the utilization of the digital in the relationship with clients. The business model is shifting, going from vertical organizations (focused on the products) to horizontal (focused on clients). The utilization of the digital does not lead to the standardization but to a customization of the offer.

There are three types of regulation; (1) the prudential regulation;(2) the activities' regulation; and (3) the regulation regarding the relationship with clients.

(1) The term prudential means minimum capital requirement. The prudential regulation wants to ensure the good adequacy between the risks carried by financial institutions and their capital. It was in the late 80's that the prudential regulation has been settled in order to restrain risk taken by banks and not anymore in order to replace the market mechanisms. Banks have to deal with solvency requirements and in order to make banks adhere to this, regulatory jurisdiction have reached an agreement in the Basel Committee. It created the Basel I, II and III regulations. These regulations tend to be more complex and more exigent about capital. The Basel I was created in 1989 and principally concerned the level of the Cooke ratio ${ }^{1}$, it had to be higher than $8 \%$. In 2004, the Basel Committee decided to implement a new capital adequacy framework, replacing the Cooke ratio, it is the Basel II. The Basel II planned a broaden cover of the banking risks and encouraged financial institutions to improve their internal management of risks. It came into effect on December 31st, 2006. Thanks to these two Basel legislations, banks' solvencies have been enhanced over the time. Nevertheless, they did not have enough to predict the insolvency issues that appeared in 2007. In this context of managing risks, financial institutions hired experts in risks and in control. These regulations impacted in a certain measure the capacity of adaption of financial institutions. After the disclosure of the systemic scale of the sub-prime crisis, the Basel III regulation proposed three major measures for banks in order to promote a higher financial stability and to support a medium-term growth. The first measure is the increase of the banks' capital (reaching in 2019; $7 \%$ of the ratio of common stock and 8,5\% of the ratio of equity funding). The second one is the improvement of the risk management of liquidity and the strengthening of the prudential requirements regarding the counterparty risk. Basel III implemented two ratios.

The first one is the Liquidity Cover ratio (LCR $)^{2}$. This ratio is to assure the capacity of financing of Banks in order to resist a liquidity crisis and to respect its commitments during at least one month. The second one is the Net Stable Funding ratio (NSFR), and concerns the capacity of banks to finance themselves at medium-term (one year). ${ }^{3}$ To finish, the third measure is the establishment of a $3 \%$ limit to the debt-authorized leverage.

In 2010, following Basel III, several institutions (OECD, BIS and the Institution of International Finance) tried to implement measures in terms of capital through global macroeconomic models (Croissance Plus, 2015).

(2) Regarding activities' regulation, it refers to the activity of insurance of management. Finance is a regulated activity; it practices go through a license given by regulators (for instance in France; ACPR or AMF). Indeed, only licensed companies can practice bank's activities. Nevertheless, the license is not an impediment to the entry of new actors, they are not forced to choose the banking status. In fact, less restrictive status exists, for instance in France the status of CIF (Advisor in Financial Investment) or IFP (Intermediary in Participative Financing). The common point of these statuses is the core of their activities; advising clients. The execution of the operations is left to traditional actors in order to avoid constraints from regulations. Regulation on activities has permitted to these new entrants to focus on client's relationship.

(3) More and more regulation regarding client's relationship has intensified and has become further intrusive in private life. Financial intermediaries are forced to find and check the real identity of the client, the source of the funds and wealth in order to make sure that products are corresponding to their financial profile. The demand from regulation to have a better knowledge about clients has different roots.

\footnotetext{
${ }^{1}$ Capital/risk-weighted assets

${ }^{2}$ LCR $=$ stock of high-quality assets/net cash outflows over a 30day time period $>100 \%$

${ }^{3} \mathrm{NSFR}=$ Available amount of stable funding/required amount of stable funding $>100 \%$ 
The event of the $11^{\text {th }}$ of September in the United States has marked a shift in client's relationship. Now, every client can be seen as a terrorist or a fraudster. A new era appeared, the era of suspicion. In fact, intermediaries are forced to inform an anti-financial crime organization if they have suspicions about their clients.

Moreover, after the financial crisis, American banks had to pay a record fine partially because of the default of information to clients (Croissance Plus, 2015). For instance, Bank of American paid more than \$55 million since 2007 and JP Morgan $\$ 30$ million.

The second root is the regulation for the consumers' protection (or in our case investor). This regulation's purpose is to think that customers must have access to information concerning an investment prior to buying it and as long as they hold it. Through the flow of comprehensive and accurate information given to him, clients must be able to judge if an investment is the sound one for them. In order to verify his knowledge, the customer has to answer to a set of questionnaire and once they have done it they will be able to do transactions. When adding up the suspicion and the ignorance, clients can have the feeling that they are not appreciated. The financial advisor becomes more occupied by doing administrative activities than giving advices to clients. Moreover, there is a "zero default" tolerance in respect of compliance, either on anti-money laundering fraud or on the categorization of clients at the opening of the relationship. Clients are becoming case-ticker and do not look closely at what they are signing.

The consequence of these regulations and of this mass approach is that, every client is categorized in a box in order to satisfy the compliance and the risk analysis; resulting in a destruction of the proximity with clients and the ability to adapt to clients' expectations. Thus these actors lost their main strength, the customization of their client's relationship. Through time, regulations will keep moving activities from traditional to non-traditional actors. Regulations' shift has caused lower returns for certain products and doing business has become costlier, pushing banks to increase their prices and to reduce their presence in some businesses (Goldman Sachs, 2015). The increase of prices has permitted the appearance of new actors charging lower prices. For instance, traditional actors have put aside some commercial activities such as lending to small and medium enterprises because of their higher risks.

In the United States, the Securities and Exchange Commission (SEC) is the organization in charge of "protecting investors, maintaining fair, orderly, and efficient markets, and facilitating capital formation». ${ }^{4}$ Under the Security Act of 1933, the Regulation D purpose was to forbid issuers from general solicitation for transaction (for example, advertisements and public websites) if they were not involved in public offering and not registered at SEC.

Start-ups were not allowed to do advertisement campaigns. In 2013, the Regulation D was amended in order to allow general solicitation in some cases; now some companies can offer or sell their securities without being enrolled at SEC, if purchasers of securities "are accredited investors and the issuer takes reasonable steps to verify that such purchasers are accredited investors. ${ }^{5}$ Therefore, in September 2013, AngelList posted on its website more than a thousand of startups looking to raise money publicly.

The more a sector is regulated the more it is stuck in the regulation and the more the "disruptive" companies find their place. The goal of these companies is to propose to clients an innovative approach far from the traditional companies. Even if the modifications of the business model are coming from the regulation nevertheless it is not the only factor permitting to understand the success of innovative companies. To conclude, by not being regulated the new actors have a competitive advantage, however it is a matter of time for regulators to implement regulations for them.

\section{What does it mean financial technologies?}

\subsection{The appearance and the enthusiasm for financial technologies}

The term Fintech is a contraction of finance and technologies. It represents innovative start-ups that use technologies in order to redesign financial and banking services. The Fintech has a 65 years old history, as most people believe that Fintech appeared when the mobile applications were developed in order to make credit card payments. But this is actually not case. The first signs of Fintech appeared in the mid 1950's with the development of the credit card allowing customers to carry no cash.

In the 1960's, the appearance of the ATM (Automated Teller Machine) has permitted customers to withdraw money without going to the bank and also to change their way to deal with their assets (Douglas and Barberis, 2014). In the 1980's, banks experienced innovative computers and software; allowing for an easier data recording. In 1990's, the explosion of internet and the booming of the e-commerce have allowed technological innovation for financial services.

\footnotetext{
${ }^{4}$ Sec.gov. 2016. SEC.gov | What We Do.

${ }^{5}$ Eliminating the Prohibition Against General Solicitation and General Advertising in Rule 506 and Rule 144A Offerings.
} 
For instance, in France, Moneo, an electronic wallet allowed customers to pay purchases with a smart card. Throughout these fifty years of development in financial technologies, consumers did not necessarily realize that they were using it almost every day. This development benefits customers and banks and allowing banks to grow overs years. A study made by the US FDIC shows that, over the last 64 years, bank's branches have increased by 355\%. Nevertheless, lately, Fintech have known a huge booming. After the financial crash in 2008, Fintech have emerged even more in order to fill the gap left by major actors. Nowadays, investors believe wholeheartedly that entrepreneurs of Fintech can transform the sector thanks to their ambition and to their boldness. The atmosphere is at the euphoria.

This augmentation in Fintech investments can be showed through two examples of success. The first one, is the First Data Corporation, a leader in the provision of e-commerce and payment processing services to different actors across the world. They provide a customized service according to regional and local market requirements. In June 2014, First Data Corporation has raised an historic $\$ 3.5$ billion in private equity thanks to various actors; $\$ 1.2$ billion from KKR (Kohlberg Kravis Roberts) a global investment firm and \$2.3 billion coming from mutual funds, hedge funds and institutions. The second example of success is represented by a peer-to-peer platform called Lending Club. At the end of 2014, Lending Club had raised almost $\$ 870$ million on the NYSE (New York Stock Exchange) through its IPO valuating the company at $\$ 8.5$ billion. This IPO was the first one for a lending platform and also the highest U.S. technological IPO of 2014.

The year 2015 was always a mitigate year for the Fintech sector. On one side, this was a successful year thanks to IPOs of various Fintech companies such as Square and First Data. These IPOs reached higher capitalization than most financial institutions. Nonetheless, this year has known the decline of relevant players. The major crash was Powa technologies, a United Kingdom Fintech company known for its mobile payment application. The company was once estimated to $£ 1.8$ billion and has collapsed into a bankruptcy administration, as the company was not able to meet its debts. However, even if some Fintech companies have failed the Fintech sector is particularly active. Investors are investing billions in thousands of Fintech start-ups in hope that such or such applicants turn out to be the "big winner".

Most of the Fintech investments are targeting the payment sector (38\% of the total investments in Fintech companies). The first battlefield of the Fintech is the payment sector, because this technology can drastically reduce costs of transaction by creating an innovative framework and an alternative to the transaction one. Nevertheless, even if the payment sector has received more investments over the last 5 years, others sectors are growing more and more due to the maturity of the market. For instance, the Insurance sector is growing promptly and is seen as the future major branch of the Fintech. These new Fintech companies are not reduced anymore to the banking sector, they are also present in others industries such as the protection of private data and the proof of existence (Croissance Plus, 2015).

The Fintech marks a new step in the banking disintermediation. In fact, Fintech companies are trying to replace not only the products of banks but also the jobs people are doing at banks. For instance, they are pretending that they can replace a banker, secure the system of payment and grant loans, even if they are doing it differently. This new form of disintermediation concerns mainly the job of a banker and also all the different kind of jobs in the world of finance. For instance, activities of retail banking, of payment, of management, of financing and of insurance are concerned.

In 2015, CB Insights Company highlighted that it is possible to do on the web or via Fintech companies every function banks used to do, for either particular or professionals clients (Croissance Plus, 2015). Thousands of Fintech companies are ready to disrupt the integrated value chain of banks by rethinking the different elements of the chain. The main goal of Fintech is to reform the financial sector by making sure they have a part of the market. In order to do so, they are using a bunch of "weapons" as new digital technologies, algorithms, studies of data, new commercial models that are more effective and more advantageous, simplified financial services, custom-made and adapted to the needs of a new generation equipped with smartphones and tablets.

Nevertheless, Fintech companies can be separated in two categories; the competitive ones and the collaborative ones. The competitive can be defined as straightforward competitors to traditional actors. The collaborative can be seen as companies wishing to help traditional actors by improving their actual position in the market. Investments in collaborative Fintech companies are higher than the ones in the competitive Fintech companies. In fact, investments in collaborative Fintech companies have known an increase of 138\% in 2015, representing almost half of the total Fintech investments. This raise underlines that on both sides there is a wish to collaborate. Even if investments in collaborative Fintech is globally higher than in competitive, it is relevant to notice that it can vary from one market to another. Taking the example of the city of New York, the percentage of investments in collaborative Fintech has increased by almost 50\% from 2010 to 2015. However, this is not the case in the United Kingdom, where the regulation has favored Fintech companies that want to compete with traditional actors. In fact, in the United Kingdom, it is the opposite, compared to the United States, 90\% of the total investments in Fintech is going to competitive ones. The chart below highlights the differences in Fintech investments allocation between market. 
Figure 1: Collaborative (in orange) Fintech Investment versus Competitive (in blue) Fintech Investments, 2015 (\$M)
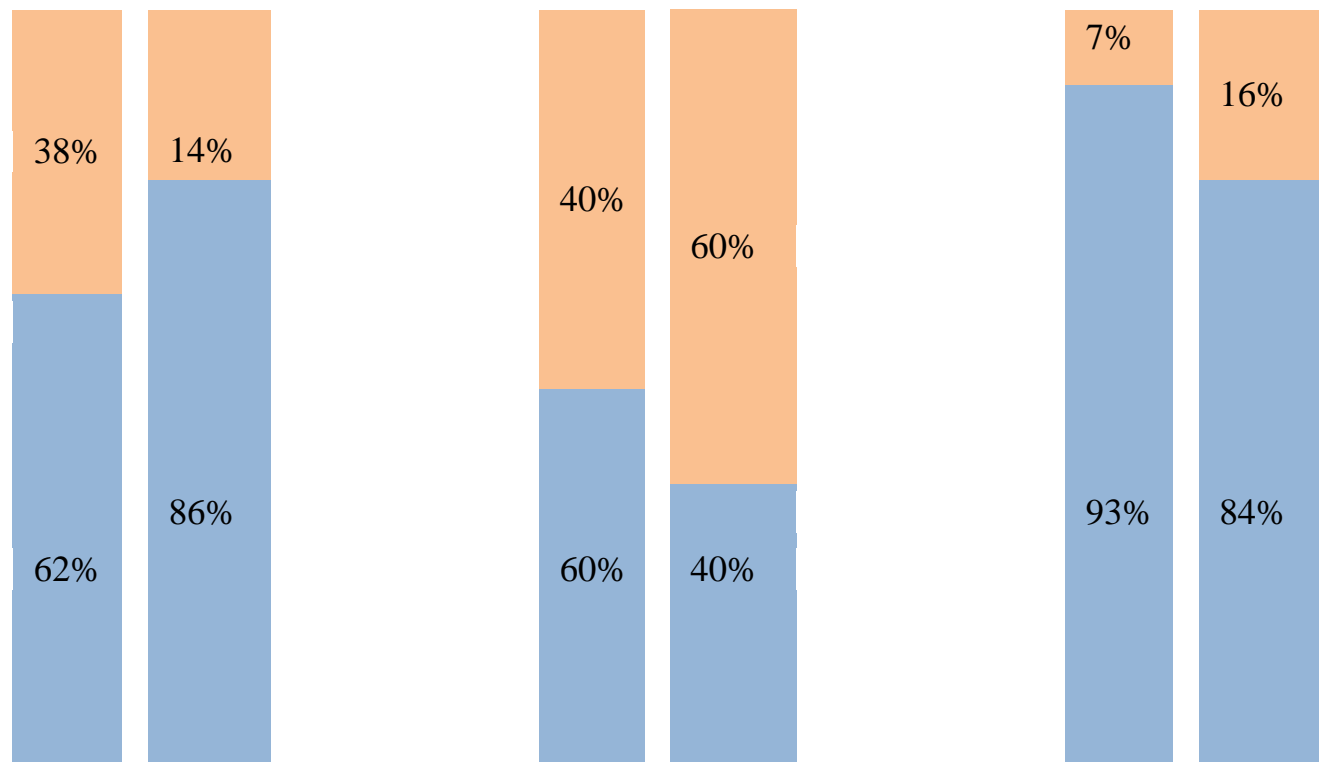

Source: Accenture, 2015

According to UrsRohner, Chairman of Credit Suisse's Board of Directors, the collaboration is the most promising option. On both sides, there are advantages, on the first hand banks can reduce cost pressure and improve their efficiency of treatments and on the other hand Fintech start-ups can maintain their activities on a long-term basis. The enthusiasm towards Fintech has been growing years after years and it is not going to stop for the moment. One interesting question would be what is making them so special?

\subsection{Fintech-a different strategy from the traditional actors}

The major difference is the relationship with clients. Indeed, clients' experience has been improving thanks to new technologies. The objectives of Fintech are to do it differently and to do it cheaper than banks. Their goals are not to create products but to propose a custom way of buying, relying on the clients' experience. Moreover, they are differentiating themselves from traditional actors thanks to their simplicity, rapidity of execution and personalized process. The business model of these Fintech companies is completely different from banks. Fintech companies heavily rely on the use of technology by levering data analytics. The development of data analytics has been possible thanks to the expansion of digital footprints, a better access and use of data (Goldman Sachs, 2015).

Technologies are making changes possible, socials network (like Facebook), electronic and mobile applications permit Fintech to offer a broader range of services. Particularly technologies have allowed customers using Fintech to live a faster, easier and cheaper experience.

Additionally, Fintech companies want to make services more accessible to customers. Taking the example of Yoyo Wallet, the Europe's fastest growing mobile wallet, its whole purpose is to "democratize" the mobile payment and loyalty services from businesses to customers. The Yoyo wallet is based on the utilization of a QR code, which let customers to scan their mobile at retailers in order to pay. In the United Kingdom, students from 40 universities use this application in campus' shops (Marketing week, February 2016).

In most cases Fintech companies focus their activities on a single proposition, they offer only one product or service. It differs completely from large traditional actors, which offer a panel of products and services (World Economic Forum, 2015). In fact, more and more consumers and companies turn away from universal banks and go to individual specialists. For instance, in order to receive and transfer funds they use now the internet or the mobile phone via Fintech companies like Venmo or Stripe. In order to manage their personal finance, they are going to use applications like e-Toro. Even if there is comfort in the use of individual services it can also be seen as an inconvenient as users have to use several Fintech in order to manage their whole monetary activities. However, it does not seem to annoy customers, as they are used to have fragmented services on their smartphones.

The financial disintermediation is not only an increase in the competition between similar actors. The new model imposed by the Fintech goes beyond digital innovations that banks should develop. It reconsiders the centralized model based on trust toward banks and states by creating a decentralized model where trust is based on the diversification of data (Croissance Plus, 2015). 
As mentioned before, new technologies have given to Fintech start-ups the opportunity to enter in markets that were usually underserved by banks. Two major examples show how Fintech fit into a breach. The Fintech has resolved for emerging countries the issue of cash. In China for instance, Fintech start-ups have grown over the years and the country became a new place for some of the largest Fintech companies in the world. For instance, Alibaba the e-commerce company is one of the major Fintech companies in the world. In 2010, Alibaba created a micro-credit company called Alipay Financial. According to the ACCA (Association of Chartered Certified Accountants), Alibaba through its partnership with two banks (Commercial Bank of China and China Constructions Bank) is representing \$2.1 billion of loans in China. Indeed, Fintech's development in China has been supported by technological changes (Lee and Kim, 2014) and also China's government policy (Douglas and Barberis, 2014). In Africa, 80\% of the population does not have a bank account, consequently they do not have a credit card nonetheless most of them have a mobile phone. This is also the case in Asian countries. According to the World Bank, across the world, 2 billion of people do not have a bank account and almost 50\% of them are in Asia. Moreover, credit card penetration rate is very low in developing countries compared to develop ones. In Asian countries, like China, South Korea, Singapore, it goes from $2 \%$ to $50 \%$. However, the mobile penetration rate in Asian countries is high, 80\% in India, 99\% in Indonesia.

Fintech in emerging countries have focused on mobile applications. A mobile application is software developed to run on a mobile terminal (smartphones and touchpads). The application must be downloaded by the user to become usable from the mobile's operating system exactly like on a classic computer. In Africa, mobiles became, thanks to Fintech, a relevant tool of e-inclusion, permitting in the absence of banking infrastructures to receive or pay salaries. In Kenya, almost $75 \%$ of the population are paying their common life's invoices; electricity bills, tuition fees, via the application M-Pesa. This application launched in 2007 is a mobile money system and one of the most successful applications in money transfer service. Thanks to their mobile phone, people with limited or restraint access to bank accounts have the possibility to send or receive money and even pay their bills.

The principle is simple; customers have to register to a registered agent - usually it is a mobile phone store. The customer is depositing cash against electronic money that they can send from their mobile phone. Once the customer has done its transactions, both parties are going to receive a SMS recapitulating the amount of the transactions and confirming it by entering a PIN number ensuring safety. If the counterparty wants to withdraw money, then he just has to go to a registered agent that will give him cash money.

Another example concerns the financing of SMEs (Small and Medium sized enterprises). A report made by FINECO of Paris EUROPLACE (2013) highlighted difficulties for the traditional model to finance the French economy. Indeed, the 2007-2008 crisis of liquidity and the crisis of the Sovereign debt in Europe (2009-...), have impacted as much banks as the European bond market. This shows the limitations of the financing model of the SMEs, depending almost exclusively on banks. In this context, the SMEs have for first priority the diversification of their source of financing. Moreover, these companies are looking for solutions adapted to their needs in terms of accessibility to these financing (Lendix, 2015). The Fintech have given SMEs an alternative way to finance themselves. The main reasons for this are multiples. For traditional actors, financing SMEs needs more expertise compared to other consumers indeed it is seen as a complex and low scale financing and due to their small loan sizes it is also seen as too costly. Actually, funding SMEs for banks or financial institutions requires a complex decision making process, for instance they need to collect a range of information in order to determine if they are going to be a "good" or "bad" applicants (Ashton and Keasey, 2003). Collecting information on the SMEs can be difficult and even impossible in cases of young SMEs. Furthermore, due to the enforcement of regulation, traditional actors have dropped the financing of SMEs even if they are seen as a dominant actor of economic activity in many developed and developing countries.

Finding appropriate funds for SMEs is critical for their success. The Fintech companies have improved their access to funding by responding to their needs. Taking the example of alternative lenders, McKinsey \& Company in 2013, made a research and shows that one third of the SMEs borrowers using marketplace-lending platform were persuaded that they would not have been able to finance somewhere else. Thanks to the marketplace-lending platform, it is easier for SMEs to have a loan and especially the process of getting it becomes uncomplicated. The SMEs can complete the loan application at its premises, no need to visit the company. Moreover, SMEs do not have to complete hundreds of papers making the process more pleasant.

In 2014, according to a study made by the International Finance Corporation and McKinsey \& Company, banks are lending to SME's across the world; approximately from $\$ 14$ trillion to $\$ 18$ trillion. Even if peer-to-peer platforms are still restrained in size, they are growing at a fast pace. Indeed, Morgan Stanley (2015) predicts that by 2020 the global peer-to-peer lending market will increase by $\$ 150$ to $\$ 490$ billion. 
Causes for the Fintech's success are multiples, the rigidity of the traditional structure, the weight of the hierarchy, of the habits, of the culture of the risk free and the lack of decision- making by individuals. Traditional companies cannot adapt themselves as easily as these innovative companies (De Vauplane, 2015).

In fact, these Fintech are benefiting from a flexible hierarchy, a capacity of taking risks and of reconsideration. It is important to keep in mind that the objectives of these Fintech are not to avoid the law or regulation but to stand themselves outside of these constraints. If they are enable to avoid them they are going to choose a status that is less inconvenient or they are going to do partnership with existing licensing companies in order to use their different licenses.

All the new platforms know how to integrate the characteristics of clients in order to propose them tailor-made solutions. They are not a model "production-distribution" but a model "adaptation-distribution". The first concern of the increase of the disintermediation is economic. Several questions are still unresolved, in ten years what will be the place of banks, financial companies and also the start-ups in the financing of this economy? The second concern is the economic and fiscal sovereignty. Indeed, the fiscal sovereignty has an increased risk of "Base Erosion and Profit Shifting". The BEPS is a term used to describe tax planning strategies that rely on mismatches and gaps that exist between the tax rules of different jurisdictions, to minimize the corporation tax that is payable overall, by either making tax profits "disappear" or shift profits to low tax operations where there is little or no genuine activity. The BEPS is used in the decentralized model of checking transaction of crypto-currencies and of new usages, which permits to develop new payment framework that are cheaper and more adapted to the needs of consumers. Nevertheless, this new framework is unusable on a large scale and out of a country's control. A basic example is a company that decides to pay its employees through a payment framework that uses crypto-currencies, how would a government be going to debit taxes?

The financial industry is one of the most regulated industries. The future of the Fintech and its possibility to take over the traditional actors heavily relies on the role of governments, regulators and international organizations.

However, Fintech find themselves in an ultimate predicament. On one hand, Fintech companies are developing a new model responding to the demand of customers and that is beneficial for them. On the other hand, regulators have to maintain their directives, which include, "financial stability, prudential regulation, conduct and fairness, competition and development". One sound example of a country where the government and regulators have succeeded to establish a constructive path is the United Kingdom. The United Kingdom is the first financial center of the world and over the years it became a relevant place for Fintech companies wishing to evolve globally. As George Osborne, former Chancellor of the Exchequer, explained «I want the United Kingdom to lead the world in developing Fintech. That's my ambition - short and sweet ». The United Kingdom Trade \& Investment (UKTI) has permitted a fruitful environment for Fintech start-ups and entrepreneurs. In fact, it is trying to bring more and more investments in the United Kingdom's Fintech sector and it is helping United Kingdom's Fintech in their desire to grow internationally (United Kingdom trade \& Investments, 2014).

Moreover, the Financial Conduct Authority (FCA), the financial regulator in United Kingdom, is the leader in figuring out the balance between the development of the Fintech industry in United Kingdom and the maintenance of a competitive and stable banking industry. Even if it is relevant for regulators and government to be supportive, Fintech companies have to be committed to build a helpful environment. Indeed, concerning compliance, Fintech companies should satisfy suitable standards. When they are doing so, it will allow them to avoid doing valuable modifications to their business model in the future and more importantly it will show to regulators their disposition to collaborate. A sound example underlying that Fintech companies should satisfy suitable standards is the marketplace lender Prosper. For almost two years, Prosper has issued loans in form of securities, which have breached different sections of the Securities Act. These sections concern the prohibition of offering or selling securities that are not registered. In 2008, the SEC (Securities and Exchange Commission) has sent to Prosper a "cease and desist" letter requiring it to take actions and to register under the Security Act. Prosper has done it successfully and set a jurisprudence for other players. Indeed, taking marketplace lenders as an example, the increased in the volume of granted loan is a relevant indicator of the success of the Fintech. Nevertheless, this increase can also grow concerns from regulators concerning their credit quality. In order to reassure regulators, marketplace lenders should supply enough information to the regulators showing them that they have high quality portfolio. Each country has a particular regulation regarding the Fintech industry. However, it would be beneficial to have a more collaborative approach at the international level, this would permit to transmit consistent directives thanks to international forums such as the Basel Committee. The development of the Fintech companies also brings fears. 
For instance, a study made by the CFA institute underlines that the automated advised knows fears, mainly regarding default from the algorithm of automated advises (46\%), the drift regarding errors in advises (30\%) and data protection $(12 \%)$. Even if some people can be reluctant to Fintech services, these are attracting billions of dollars and are also challenging banks.

\section{Conclusion}

Fintech started in 1950's, however, it was only after the 2007-2008 financial crisis that Fintech expanded on a proportion never seen before. This expansion has been driven by technological innovation, consumer's shifts, higher level of regulation for established financial companies. All together a breach has been open-up and Fintech companies have decided to take it. Over the years, the appetite for Fintech start-ups has pushed investors to invest billions in numerous Fintech start-ups but also accelerators, incubators in order to find the next "big winner". The Fintech startups have attracted a lot of attention from investors thanks to their completely different business model, focused on a single product or offer and dedicated to customers' needs. Even if technological innovations in financial services and products have been welcomed in overall it has also brought concerns to regulators that have the obligation to regulate the financial environment.

The Fintech start-ups have attacked not only many jobs of the banks by bringing new ways to fund ourselves and to use money. Moreover, they have challenged the business model and the attitude of banks. Through all of that Fintech have revolutionized the Finance Industry.

Banks have three different ways to take over the challenge, either do open innovation or collaborate or invest, some of the banks did it with success. According to the point of view that a person takes on the Fintech, he will have different thoughts. Media are making a lot of noise regarding Fintech and the possibility for its expansion, although these startups are dusting operation modes, banks still retain a largely dominant position, sometimes overwhelming. The expansion of the Fintech has been fast over the last decades and has revolutionized the finance industry, consequently the expected growth could be even more important in the near future.

\section{References}

Accenture. 2015. The Future of Fintech and Banking.

Allen, F., McAndrews, J., and Strahan, 2002. E-Finance: An Introduction: Journal of Financial Services Research 22, $5-27$.

Ashton J., Keasey K., 2003, Lending decision making and the Competition Commission report on the provision of banking services to small firms. Journal of Financial Regulation and Compliance 11, 26-36.

Belleflamme P., Lambert, T., and Schwienbacher A., 2015. Crowdfunding. Information Economics and Policy33,1128.

Cichowlas A., 2015. Technologie et Transformation des services bancaires: L'exemple de Technovision de Capgemini.

Claessens, S. Glaessner, T., and Klingebiel, D., 2002.Reshaping the Financial Landscape Around the World, Journal of Financial Services Research 22, 29-61

Croissance Plus. 2015. Fintech 2020: Reprendre l'initiative.

De Vauplane H. 2015. Les Fintech et la réglementation bancaire et financière. Revue Banque. Banques \& Stratégie $339,32-36$.

Douglas W. A. and J. Barberis, 2015. Regulating FinTech Innovation: A Balancing Act, Asian Institute of international Financial Law

Eriksson, K. and Marquardt, R., 2001. Is relationship theory applicable to Internet bank relationships? working paper

Fight, A. 2002, E-finance, John Wiley and Sons Ltd

Goldman Sachs, 2015. The Future of Finance, the rise of the new Shadow Bank.

Gowland, D., 1991. Financial innovation in theory and practice, Oxford.

Klein O., 2015. Banque et nouvelles technologies: La nouvelle donne. Revue de l'Association d'Economie Financière 120.

Kotler, P., Bowen, J.T. and Makens, J.C., 2010. Marketing for hospitality and tourism. (5th ed.). Boston: Pearson.

Krugman, P., 2008. The Return of Depression Economics and the Crisis of 2008,

W. W. Norton \& Company

Lee, T., and Kim, H., 2015. "An Exploratory Study on Fintech Industry in Korea: Crowdfunding Case, working paper.

McKinsey \& Company, 2013. Digital Models for a Digital Age: Transition and Opportunity in Small Business Banking. 
Meuter, M. L., Ostrom, A., Roundtree, R. I., \& Bitner, M. J., 2000. Self-service technologies: Understanding customer satisfaction with technology-based service encounters. Journal of Marketing 64, 50-64.

Morgan Stanley. 2015. Global Marketplace Lending: Disruptive Innovation in Financial Services.

Pujari, D., 2004. Self-service with a smile? International Journal of Service Industry Management 15: 200-219.

Reisman, A., and Zhao, L.,1991. A taxonomy of technology transfers transaction types. Journal of Technology Transfer, 16 (2), 38-42.

Sec.gov. 2016. SEC.gov | What We Do. https://www.sec.gov/about/whatwedo.shtml.

Shahrokhi M., 2008. E-finance: status, innovations, resources and future challenges. Managerial Finance 34, 365 - 398.

Takieddine S., Sun J. 2015. Electronic Commerce Research and Applications 14. 361-371.

Tellervision and Mars. 2016. Branches of the Future Retain Similarities with Today's Model, 1463.

Tih, S., and Ennis, S., 2007. Cross-industry analysis of consumer assessments of internet retailers' service performances. International Journal of Retail \& Distribution Management, 344, $290-307$.

UK trade \& Investments, 2014. EY, Landscaping UK Fintech.

Mikoajewicz-Woniak A., and Scheibe A., 2015. Virtual currency schemes - the future of financial services. Foresight.17, $365-377$.

World Economic Forum. 2015. Collaborative Innovation Transforming Business, Driving Growth.

World Economic Forum. 2015. The Future of Financial Services: How disruptive innovations are reshaping the way financial services are structured, provisioned and consumed.

World Economic Forum. 2015. The Future of Fintech: A Paradigm Shift in Small Business Finance.

World Retail Banking Report, 2015.

Worthington S., and Welch P. 2011. Banking without the banks. International Journal of Bank Marketing 29, 190-201.

Yang J., and Klassen K. J., 2008. How financial markets reflect the benefits of self-service technologies. Journal of Enterprise Information Management 21, 448-467. 